36. Bonaiuto S, Rocca WA, Lippi A, et al. Education and occupation as risk factors for dementia: a population-based casecontrol study. Neuroepidemiology 1995;14:101-109.

37. Hofman A, Rocca WA, Brayne C, et al. The prevalence of dementia in Europe: a collaborative study of 1980-1990 findings. Int $J$ Epidemiol 1991;20:736-748.

38. Rocca WA, Hofman A, Brayne C, et al. Frequency and distribution of Alzheimer's disease in Europe: a collaborative study of 1980-1990 prevalence findings. Ann Neurol 1991;30:381390.

39. Bachman DL, Wolf PA, Linn R, et al. Prevalence of dementia and probable senile dementia of the Alzheimer type in the Framingham Study. Neurology 1992;42:115-119.

40. Beard CM, Kokmen E, O'Brien PC, Kurland LT. The prevalence of dementia is changing over time in Rochester, Minnesota. Neurology 1995;45:75-79.

41. French LR, Schuman LM, Mortimer JA, Hutton JT, Boatman RA, Christians B. A case-control study of dementia of the Alzheimer type. Am J Epidemiol 1985;121:414-421.

42. Chandra V, Philipose V, Bell PA, Lazaroff A, Schoenberg BS. Case-control study of late-onset "probable Alzheimer's disease." Neurology 1987;37:1295-1300.

43. Shalat SL, Seltzer B, Baker EL. Occupational risk factors and Alzheimer's disease: a case-control study. J Occup Med 1988; 30:934-936.

44. Li G, Shen YC, Li YT, Chen CH, Zhau YW, Silverman JM. A case-control study of Alzheimer's disease in China. Neurology 1992;42:1481-1488.

45. Dartigues JF, Gagnon M, Mazaux JM, et al. Occupation dur- ing life and memory performance in nondemented French elderly community residents. Neurology 1992;42;1697-1701.

46. Fratiglioni L, Ahlbom A, Viitanen M, Winblad B. Risk factors for late-onset Alzheimer's disease: a population-based casecontrol study. Ann Neurol 1993;33:258-266.

47. The Canadian Study of Health and Aging: risk factors for Alzheimer's disease in Canada. Neurology 1994;44:20732080.

48. Sobel E, Davanipour Z, Sulkava R, et al. Occupations with exposure to electromagnetic fields: a possible risk factor for Alzheimer's disease. Am J Epidemiol 1995;142:515-524.

49. Kukull WA, Larson EB, Bowen JD, et al. Solvent exposure as a risk factor for Alzheimer's disease: a case-control study. Am J Epidemiol 1995;141:1059-1071.

50. Sobel E, Dunn M, Davanipour Z, Qian Z, Chui HC. Elevated risk of Alzheimer's disease among workers with likely electromagnetic field exposure. Neurology 1996;47:1477-1481.

51. Persson G, Skoog I. A prospective population study of psychosocial risk factors for late-onset dementia. Int J Geriatric Psychiatry $1996 ; 11: 15-22$.

52. Schmand B, Lindeboom J, Hooijer C, Jonker C. Relation between education and dementia: the role of the test bias revisited. J Neurol Neurosurg Psychiatry 1995;59:170-174.

53. Hier DB, Wazach JD, Gorelick PB, Thomas J. Predictors of survival in clinically diagnosed Alzheimer's disease and multiinfarct dementia. Arch Neurol 1989;46:1213-1216.

54. Crimmins EM, Hayward MD, Saito Y. Differentials in active life expectancy in the older population of the United States. J Gerontol 1996;51B:S111-S120.

\title{
Cognitive test performance among nondemented elderly African Americans and whites
}

\author{
J.J. Manly, PhD; D.M. Jacobs, PhD; M. Sano, PhD; K. Bell, MD; C.A. Merchant, MD; \\ S.A. Small, MD; and Y. Stern, PhD
}

Article abstract-We examined the neuropsychological test performance of a randomly selected community sample of English-speaking non-Hispanic African American and white elders in northern Manhattan. All participants were diagnosed as nondemented by a neurologist, whose assessment was made independent of neuropsychological test scores. African American elders obtained significantly lower scores on measures of verbal and nonverbal learning and memory, abstract reasoning, language, and visuospatial skill than whites. After using a stratified random sampling technique to match groups on years of education, many of the discrepancies became nonsignificant; however, significant ethnic group differences on measures of figure memory, verbal abstraction, category fluency, and visuospatial skill remained. Discrepancies in test performance of education-matched African Americans and whites could not be accounted for by occupational attainment or history of medical conditions such as hypertension and diabetes. These findings emphasize the importance of using culturally appropriate norms when evaluating ethnically diverse elderly for dementia.

NEUROLOGY 1998;50:1238-1245

Accurate assessment of cognitive functioning is a crucial component in the identification of dementia among elderly persons. To increase the sensitivity and specificity of cognitive tests, neuropsychologists must be aware of all factors which might confound the interpretation of test scores, including age, education, gender, and cultural background. However, the relation of ethnic background and cultural expe-

From the Departments of Neurology (Drs. Manly, Jacobs, Sano, Bell, Merchant, Small, and Stern) and Psychiatry (Dr. Stern), the Gertrude H. Sergievsky Center (Drs. Manly, Jacobs, Sano, Bell, Merchant, Small, and Stern), and the Taub Center for Alzheimer's Disease Research in the City of New York (Drs. Manly, Jacobs, Sano, Bell, Merchant, Small, and Stern), Columbia University College of Physicians and Surgeons, New York, NY.

Supported by federal grants AG07232 and AG08702.

Received May 28, 1997. Accepted in final form December 2, 1997.

Address correspondence and reprint requests to Dr. Y. Stern, Gertrude H. Sergievsky Center, 630 West 168th Street, New York, NY $10032-3702$. 
rience to neuropsychological test performance is not well understood, ${ }^{1}$ especially among the elderly. ${ }^{2}$ Previous studies have compared the performance of ethnic groups on intelligence tests, ${ }^{3-6}$ screening measures such as the Mini-Mental State Examination (MMSE), ${ }^{7-9}$ and some formal neuropsychological measures. ${ }^{10-17}$ These studies generally indicate that ethnic minorities obtain lower scores on cognitive measures, even after correcting for differences in years of education and socioeconomic status.

Few studies exist that focus on the neuropsychological test performance of ethnically diverse elders. Studies of nondemented elderly have found that African Americans obtain lower scores on measures of naming, ${ }^{18}$ and that Spanish-speaking individuals obtain lower scores on measures of figure memory, abstraction, fluency, comprehension, and visuospatial skill. ${ }^{19}$ Results of research among ethnically diverse elderly with Alzheimer's disease are mixed. One study ${ }^{20}$ reported significant differences between African American and white elders with Alzheimer's disease on measures of naming and construction, even after controlling for differences in age, education, everyday functioning ability, severity of dementia, and duration of disease. However, another study $^{21}$ reported that among a small number of African Americans $(\mathrm{n}=11)$ and whites $(\mathrm{n}=32)$ with Alzheimer's disease, there were no significant ethnic differences on measures of naming, picture vocabulary, verbal abstraction, verbal list learning, and pragmatic language use after controlling for MMSE score and years of education. To date there have been no studies focusing on African American elders using randomly selected community-based participants. Studies of random community samples are invaluable because elderly ethnic minorities, especially those with low educational attainment, are not well represented in referral-based clinics. Therefore, findings of previous studies among African American and other ethnically diverse elderly are not generalizable to the community as a whole.

Many previous studies that compare neuropsychological test scores of different ethnic groups use covariance or matching procedures to equate groups on years of education. However, matching on quantity of formal education does not necessarily mean that the quality of education received by each ethnic group is comparable. Therefore, disparate school experiences could explain why ethnic minorities obtain lower scores on cognitive measures after controlling for years of education.

The purpose of the current study was to compare the performance of nondemented African American and white elders on a number of formal neuropsychological measures. The neurologist's diagnosis was used as a gold standard for the selection and addition of nondemented individuals to the current study, since functional and neurologic information is theoretically less susceptible to cultural or educational bias compared with cognitive measures. We hypothesized that African American elders would obtain lower scores on measures of verbal list learning, verbal abstraction, naming, and construction (drawing) compared with whites, and that discrepancies between ethnic groups on measures of naming and construction would remain significant after controlling for years of education and occupational attainment. We also hypothesized that the effect of ethnicity on test performance would not change after controlling for medical conditions that occur with greater frequency among African Americans, such as hypertension and diabetes. Our study was conducted with randomly selected participants in a large-scale, community-based epidemiologic study of aging and dementia; therefore, our results are generalizable to the population from which our sample is drawn.

Methods. Research participants. The current study included participants in the Washington Heights Inwood Columbia Aging Project (WHICAP), a community-based, epidemiologic study of dementia in the ethnically diverse neighborhoods of northern Manhattan, NY. The WHICAP study follows a random sample of elderly Medicare recipients residing in census tracts of Washington Heights and Inwood. The population from which participants were drawn was comprised of individuals from several different countries of origin and represented three broadly defined ethnic categories (i.e., Hispanic, African American, and white). Some participants who describe themselves as African American were born and educated in the West Indies. There is also a large community of elderly European Jewish immigrants who reside in northern Manhattan. The overall participation rate of individuals eligible for the WHICAP study was higher than $70 \%$.

Inclusion/exclusion criteria. All participants were age 65 years and older, and had complete data on our neuropsychological test battery. Participants were included if they self-identified their ethnicity as (1) white or black and (2) non-Hispanic, and performed the neuropsychological battery in English. Participants were asked to categorize how well they spoke English: very well, well, or not well. The current study included only those participants who said they spoke English very well. Potential participants were excluded if they had a history of Parkinson's disease, stroke, head injury with loss of consciousness, or alcohol abuse. Only WHICAP participants who showed no neurologic or functional signs of dementia were included in the current analyses. This determination was made on the basis of a neurologist's clinical examination, which included a rating of daily functioning (see the following description of procedures). In other words, the neurologist's diagnosis was used as a "gold standard" for the absence of dementia, as the neurologic assessment was made independent of the participant's performance on the neuropsychological battery.

Procedure. Medical evaluation. A neurologist recorded medical history and medications in a semistructured format. Neurologic and brief physical examinations were performed, including assessment of extrapyramidal signs. Functional status was assessed using part 1 of the Blessed Dementia Rating Scale ${ }^{22}$ (BDRS), and the Schwab and England rating scale of activities of daily living. ${ }^{23}$ The short version of the Blessed Memory Information and 
Concentration Test ${ }^{24}$ was also administered. From this information, the neurologist determined whether the participant met criteria for dementia, independent of the neuropsychological test scores.

Neuropsychological battery. The neuropsychological measures used in the current study were selected to assess cognitive functions that are typically affected in dementia. The evaluation included measures of learning and memory, orientation, abstract reasoning, language, and visuospatial ability. Specific ability areas assessed and tests administered include verbal list learning and memory (Selective Reminding Test ${ }^{25}$ [SRT]), nonverbal memory (multiple-choice version of the Benton Visual Retention Test $^{26}$ [BVRT]), orientation (items from the MMSE ${ }^{27}$ ), verbal reasoning (Similarities subtest of the Wechsler Adult Intelligence Scale-Revised ${ }^{28}$ [WAIS-R]), nonverbal reasoning (Identities and Oddities subtest of the Mattis Dementia Rating Scale ${ }^{29}$ ), naming (15-item version of the Boston Naming Test ${ }^{30}$ ), letter fluency (Controlled Word Association $^{31}$ ), category fluency (animals, food, and clothing, using procedures from the Boston Diagnostic Aphasia Examination $^{32}$ [BDAE]), auditory comprehension (first six items of the Complex Ideational Material subtest of the $\mathrm{BDAE}^{32}$ ), repetition (high-frequency phrases of the $\mathrm{BDAE}^{32}$ ), visuoconstruction (Rosen Drawing Test ${ }^{33}$ ), and visuoperceptual skills (multiple-choice matching of figures from the BVRT $\left.^{26}\right)$.

Neuropsychological criteria. Participants in the current study showed no neurologic or functional signs of dementia. However, because the neurologist's diagnosis was independent of the neuropsychological test scores, it was possible for the pattern of performance on neuropsychological measures to be "sufficient for the diagnosis of dementia." Performance on the neuropsychological battery was assessed using a fixed paradigm, which was compared with a series of cutoff scores developed in a pilot study in the community. ${ }^{34}$ No adjustments were made in cutoff scores or subject scores according to educational attainment. Using this paradigm, participants met criteria for "cognitive impairment sufficient for the diagnosis of dementia" if they scored below cutoffs in at least two of three memory categories (i.e., verbal list learning, delayed verbal memory, or figure memory) and below cutoffs in at least two other cognitive areas (i.e., orientation, abstract reasoning, language, and visuospatial ability).

Occupation. Each participant's primary occupation was recorded and classified according to US Census categories (i.e., student, housewife, unskilled/semiskilled, skilled trade or craft, clerical/office worker, manager business/government, and professional/technical). Housewives who had been employed out of the home for more than 10 years were classified according to that occupation. For the statistical analyses of the effect of occupation, we grouped the classifications into low (unskilled/semiskilled, skilled trade or craft, and clerical/office worker) and high (manager business/government and professional/technical) levels.

Statistical analyses. ANOVAs were performed to compare the two ethnic groups on age, education, and functional status as measured by the Schwab and England, and BDRS functional scales. Chi-squared analyses were used to compare proportions of whites versus African Americans whose performance on neuropsychological mea- sures met criteria for cognitive impairment sufficient for the diagnosis of dementia using the established paradigm.

MANOVAs were used to compare the overall neuropsychological performance of the African American group with the white group. Fifteen measures from the test battery were included as dependent variables in a two-group MANOVA: total raw scores for immediate recall, delayed recall, delayed recognition, and percent loss (last trialdelayed recall/last trial $\times 100$ ) from the SRT; BVRT matching and recognition memory; 15-item Boston Naming Test; BDAE repetition; BDAE comprehension; Mattis Identities and Oddities subtest; MMSE Orientation; number correct on the Rosen Drawing Test; age-corrected, scaled score on WAIS-R Similarities; and mean number of words generated over three 60-second trials for both letter and category fluency. Post hoc ANOVAs were performed to determine which neuropsychological measures contributed significantly to the overall multivariate effect. To reduce the likelihood of type I error, an alpha level of $p<0.01$ was used to determine statistically significant univariate differences.

We anticipated that ethnic group differences in education (as reflected by number of school years completed) or occupational attainment could potentially explain discrepancies between African Americans and whites on the neuropsychological tests. Therefore, we planned two analytical strategies to attempt to correct for differences in these demographic variables between the ethnic groups.

First, the multivariate analysis described earlier was reanalyzed, but with the effect of ethnicity assessed after years of education was entered as a covariate (MANCOVA). Post hoc ANCOVAs were performed to determine statistically significant univariate differences, again using the $p<0.01$ significance criterion. To determine if occupational attainment accounted for any ethnic differences, we repeated these analyses using occupational status (low and high) as an additional covariate.

The second strategy employed was to select a subsample of African American and white participants who were matched on educational level. This was accomplished using stratified random sampling. The original sample was stratified by ethnic group (African American, white) and educational attainment (i.e., 0 to 3,4 to 7,8 to 11,12 to 15 , or 16 to 20 years). Within each ethnicity-by-education stratum, a random sample of subjects was selected using the SPSS sample function (SPSS for Windows, release 6.0, 1993; SPSS, Inc.; Chicago, IL). The same number of participants was selected within each ethnicity-by-education stratum. Overall neuropsychological test performance of the two ethnic groups, now matched on education, was then compared using MANOVA, as described previously. We repeated these analyses using occupational attainment as a covariate to examine whether occupational attainment accounted for any remaining ethnic group differences.

Secondary analyses. The possible influence of medical variables on ethnic differences in neuropsychological test performance was examined within the education-matched sample. History of hypertension, diabetes, cardiac disease, thyroid disease, and chronic obstructive pulmonary disease (COPD) was recorded categorically (i.e., yes/no) during the medical evaluation. For the following analyses, an individual was considered to have cardiac disease if they reported 
history of congestive heart failure, valvular heart disease, angina, atrial fibrillation, or another arrhythmic disorder. The frequency of each of the five medical conditions within African American and white groups was compared using chi-square tests. Then, the effects of each medical condition (history present, absent) and ethnic group membership (African American, white) on the 15 neuropsychological test scores were evaluated within five separate $2 \times$ 2 MANOVAs. These analyses would determine (1) if presence of a medical condition affected neuropsychological test performance significantly and (2) if ethnic group membership had a significant effect on test performance independent of the medical variables.

Results. Entire sample. A total of 317 African American and 147 white elders were selected for the current study. The African American group had an average age of $76.3 \pm 6.5(\mathrm{SD})$ years, an average education of $9.3 \pm 3.4$ years, and $74 \%$ were women. Whites had an average age of $76.3 \pm 7.5$ years, an average of $12.5 \pm 3.6$ years of education, and $67 \%$ were women. African Americans and whites were comparable in terms of age $(\mathrm{F}[1,462]=0.0, p=0.94)$, but the African American group had significantly fewer years of education $(\mathrm{F}[1,462]=87.0, p<0.000)$. The proportion of women in each group did not differ by ethnicity ( $\mathrm{n}=464, \chi^{2}[1 \mathrm{df}]=2.5, p=0.12$ ). A significantly higher proportion of whites had high occupational attainment $(32 \%)$ compared with African Americans (14\%;n $=455, x^{2}$ [1 df] $=19.9, p<0.001$ ).

Of the whites, $40 \%$ were born outside the United States; however, $73 \%$ of these immigrants came before 1950 and all immigrated before 1965. Among the African American participants, $8 \%$ were not born in the United States. Fiftyfive percent of these African American immigrants came to the United States before 1950, and all came before 1970 . English is the predominant language spoken at home for $84 \%$ of the whites and $99 \%$ of the African Americans.

African Americans and whites were comparable in terms of everyday functional status, as measured by the physician's ratings of percent independence (Schwab and England scale; F[1,424] $=2.2, p=0.14$ ) and activities of daily living (BDRS functional scale; $\mathrm{F}[1,424]=0.1, p=$ 0.81 ). On average, African Americans were rated as $83.9 \pm$ $21.2 \%$ independent, and had a mean BDRS functional score of $1.4 \pm 2.0$. Whites were rated as $87.3 \pm 20.6 \%$ independent on average and had a mean score of $1.4 \pm 2.8$ on the BDRS functional scale.

All participants in the current study were diagnosed by a neurologist as nondemented, as is reflected in the high average ratings of functional ability in both groups. However, we wanted to compare the proportion of African Americans and whites who obtained neuropsychological test scores that, according to the established paradigm, met criteria for "cognitive impairment sufficient for a diagnosis of dementia." Using established cutoffs and criteria as described earlier, $21 \%$ of the African American elders had neuropsychological test scores sufficient for a diagnosis of dementia, compared with $11 \%$ of the whites $(n=464$, $\left.\chi^{2}[1 \mathrm{df}]=7.7, p=0.006\right)$.

We were primarily interested in the scores of African Americans and whites on individual neuropsychological measures. MANOVA revealed that, overall, the neuropsychological test scores of African Americans were significantly lower than the scores of whites $(F[15,410]=8.39$, $p<0.000$ ). Follow-up univariate testing showed that African Americans scored significantly lower than whites on measures of verbal learning and memory, figure memory, abstract reasoning, language, and visuospatial ability. African Americans obtained lower scores than whites on MMSE Orientation, but this difference was not quite significant at the $p<0.01$ level (table 1 ).

A MANCOVA, which included years of education as a covariate, was performed on the entire sample to determine if the ethnic group differences in test performance would remain even after the group difference in educational attainment was taken into account. This analysis revealed that even after equating the two groups statistically on education, the scores of whites were still significantly higher than the scores of African Americans $(\mathrm{F}[15,409]=11.79, p<0.000)$. As seen in table 1 , post hoc ANCOVAs showed that ethnic group differences on measures of verbal list learning, delayed verbal recall (but not percent loss over time), figure memory, abstract reasoning, word fluency, and visuospatial ability remained significant after accounting for education. Results did not change when occupational attainment (high, low) was added as an additional covariate in either multivariate or univariate comparisons.

Education-matched sample. The stratified sampling procedure described earlier was used to create equal groups of African American and white elders who were matched on years of education. From the original sample, 254 participants (127 whites and 127 African Americans) were selected. The white group had a mean age of $76.5 \pm$ 7.5 years, an average education of $11.7 \pm 3.1$ years, and was $69 \%$ female. The African American group was on average $74.9 \pm 6.0$ years old, had $11.5 \pm 3.0$ years of education, and was $69 \%$ female. The two groups were equivalent in terms of age $(\mathrm{F}[1,252]=3.5, p=0.06)$, educational attainment $(\mathrm{F}[1,252]=0.2, p=0.64]$ and proportion of women in the sample $\left(\mathrm{n}=254, \chi^{2}[1 \mathrm{df}]=0.0, p=0.9\right)$. In this matched sample, ethnic groups were not significantly different with respect to occupational status, because equal numbers of African Americans (22\%) and whites (24\%) were classified as having attained high-level occupations.

The African American and white groups created by the stratified random sampling method were also equivalent on both functional measures: the Schwab and England $(\mathrm{F}[1,229]=0.1, p=0.83)$ and the BDRS functional scales $(\mathrm{F}[1,229]=0.1, p=0.75)$. African Americans were rated as $85.9 \pm 21.2 \%$ independent on average, and had a mean BDRS functional score of $1.4 \pm 2.1$. Whites were rated as $86.8 \pm 21.5 \%$ independent on average, and had a mean score of $1.5 \pm 3.0$ on the BDRS functional scale.

Unlike the nonstratified sample, the functional status and nondemented diagnosis of all participants was reflected in the proportion of African Americans who met criteria for cognitive impairment sufficient for a diagnosis of dementia (13\%). This proportion was not significantly different from the white group, in which $9 \%$ had neuropsychological test scores that met criteria for cognitive impairment $\left(\mathrm{n}=254 ; \chi^{2}[1 \mathrm{df}]=1.0, p=0.32\right)$.

The education-matched groups were then compared on overall neuropsychological test performance using MANOVA. This analysis revealed that African Americans obtained significantly lower scores on the neuropsychological test battery than whites $(\mathrm{F}[15,220]=3.42, p<0.000)$. 


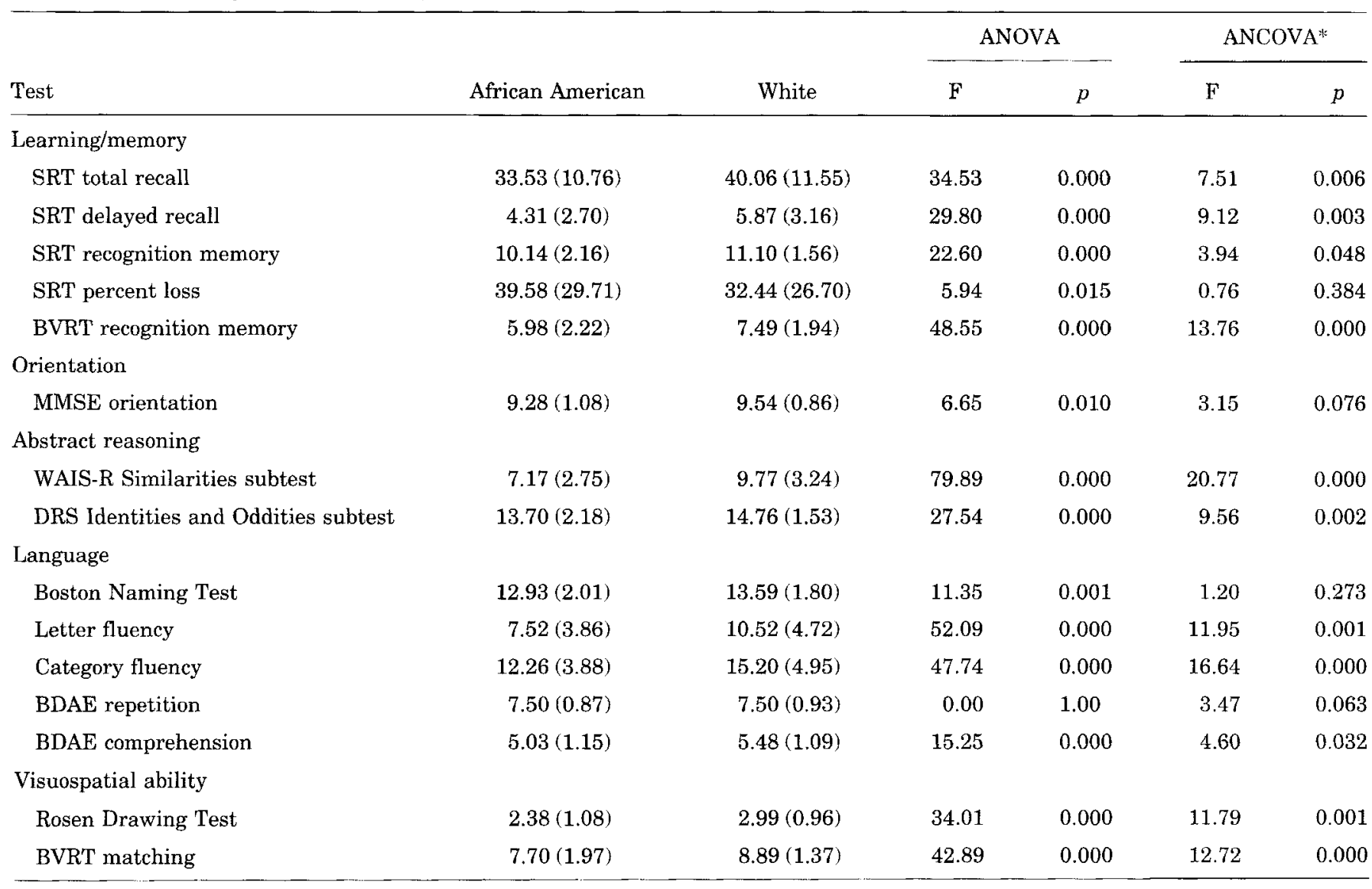

* Effect of ethnicity after covarying for years of education.

$\mathrm{SRT}=$ Selective Reminding Test; BVRT = Benton Visual Retention Test; MMSE = Mini-Mental State Examination; WAIS-R = Wechsler Adult Intelligence Scale-Revised; DRS = Dementia Rating Scale; BDAE = Boston Diagnostic Aphasia Examination.

Table 2 shows the results of post hoc ANOVAs, which indicated that the African American group scored significantly lower than whites on measures of figure memory (BVRT recognition), abstract reasoning (WAIS-R Similarities), language/executive functioning (category fluency), and visuospatial ability (Rosen Drawings Test and BVRT matching). There were no ethnic differences on measures of verbal learning and memory (SRT total and delayed recall) or delayed recall when scores were corrected for the amount of material initially attained (SRT percent loss). The effect of ethnic group on test performance in both multivariate or univariate models did not change when occupational attainment was added as a covariate.

Effect of medical variables. We wondered whether differences in frequency of various medical conditions between whites and African Americans would account for the significant discrepancies in neuropsychological test scores we observed between the education-matched ethnic groups. Approximately $64 \%$ of the African American group reported having a history of hypertension, compared with $36 \%$ of the whites $\left(\mathrm{n}=250 ; \chi^{2}[1 \mathrm{df}]=19.85, p=0.000\right)$. A higher proportion of African Americans (16\%) reported having diabetes compared with whites $\left(7 \% ; \mathrm{n}=250 ; \chi^{2}\right.$ $[1 \mathrm{df}]=4.73, p=0.030$ ). Chi-square analyses showed that frequencies of cardiac disease, thyroid disease, and COPD were not different between the two ethnic groups $(p>$ 0.05 for all comparisons).

We performed a set of five MANOVAs to determine if the effect of ethnicity was still significant after the effects of each medical condition were taken into account. None of the medical conditions had significant main effects on overall neuropsychological test performance, and the effect of ethnicity remained significant after accounting for the presence of each medical condition. The $\mathrm{F}$ values for the effect of ethnicity on overall neuropsychological test performance after accounting for the presence of each medical condition are as follows: hypertension $(\mathrm{F}[15,216]=2.96$, $p<0.000)$, diabetes $(\mathrm{F}[15,215]=3.57, p<0.000)$, cardiac disease $(F[15,216]=3.62, p<0.000)$, thyroid disease $(\mathrm{F}[15,214]=3.42, p<0.000)$, and $\mathrm{COPD}(\mathrm{F}[15,216]=$ $3.59, p<0.000$ ).

Discussion. The current study investigated the neuropsychological test performance of nondemented African American and non-Hispanic white elders. We found that among randomly selected, communitybased participants, African Americans obtained lower scores on measures of learning and memory, abstract reasoning, fluency, and visuospatial ability compared with whites, even after correcting for differences in educational attainment, occupational status, and history of various medical conditions. The current investigation attempted to address methodologic problems of previous studies of African American elders by using a large, randomly selected group and a comprehensive 
Table 2 Mean (SD) cognitive test scores of African American $(n=127)$ and white $(n=127)$ elders drawn from a stratified random sample and matched on educational attainment

\begin{tabular}{|c|c|c|c|c|}
\hline \multirow[b]{2}{*}{ Test } & \multirow[b]{2}{*}{ African American } & \multirow[b]{2}{*}{ White } & \multicolumn{2}{|c|}{ ANOVA } \\
\hline & & & $\mathrm{F}$ & $p$ \\
\hline SRT total recall & $36.91(10.73)$ & $39.70(11.28)$ & 4.05 & 0.045 \\
\hline SRT delayed recall & $5.03(2.83)$ & $5.81(3.09)$ & 4.31 & 0.039 \\
\hline BVRT recognition memory & $6.64(2.03)$ & $7.46(1.99)$ & 10.12 & 0.002 \\
\hline \multicolumn{5}{|l|}{ Orientation } \\
\hline MMSE orientation & $9.23(1.26)$ & $9.52(0.90)$ & 4.35 & 0.038 \\
\hline \multicolumn{5}{|l|}{ Abstract reasoning } \\
\hline Boston Naming Test & $13.41(1.89)$ & $13.52(1.85)$ & 0.20 & 0.658 \\
\hline Letter fluency & $9.10(4.07)$ & $10.19(4.78)$ & 3.76 & 0.054 \\
\hline Category fluency & $13.17(4.11)$ & $14.91(4.83)$ & 9.55 & 0.002 \\
\hline $\mathrm{BDAE}$ repetition & $7.65(0.71)$ & $7.47(0.97)$ & 2.78 & 0.097 \\
\hline BDAE comprehension & $5.19(1.06)$ & $5.45(1.15)$ & 3.43 & 0.065 \\
\hline \multicolumn{5}{|l|}{ Visuospatial ability } \\
\hline Rosen Drawing Test & $2.58(1.01)$ & $2.98(0.95)$ & 9.93 & 0.002 \\
\hline BVR'T matching & $8.22(1.76)$ & $8.81(1.43)$ & 8.41 & 0.004 \\
\hline
\end{tabular}

SRT $=$ Selective Reminding Test; BVRT $=$ Benton Visual Retention Test; MMSE = Mini-Mental State Examination; WAIS-R = Wechsler Adult Intelligence Scale-Revised; DRS = Dementia Rating Scale; BDAE = Boston Diagnostic Aphasia Examination.

neuropsychological battery, and by accounting for demographic or medical variables that might explain ethnic group differences.

All participants in the current study were diagnosed as nondemented by a neurologist, and the ethnic groups were equivalent on measures of daily functioning. However, the neurologist's diagnosis was independent of performance on neuropsychological measures, and therefore it was possible for participants to be functionally and neurologically normal but to have cognitive test scores sufficient for the diagnosis of dementia, according to a previously defined paradigm. Since these elders did not have functional impairment, they would not be diagnosed with dementia in the clinical setting; however, we found that African American elders were more likely to meet criteria for cognitive impairment than their white counterparts based on neuropsychological test performance alone.

After matching on educational attainment, we found that the proportion of individuals within each ethnic group who met criteria for cognitive impairment sufficient for the diagnosis of dementia became equal. Nevertheless, even after matching African American and white groups on years of education and correcting for occupational attainment, significant ethnic group discrepancies persisted on mea- sures of figure memory, verbal abstraction, category fluency, drawing, and figure matching. Caution is warranted when interpreting the results of African American elders on these individual measures, and further study is needed to determine the source of the discrepancies in performance between the two ethnic groups.

We initially attempted to correct for differences in years of education using covariance. However, this statistical procedure assumes that the relationship of the covariate (years of education) to the dependent variable (cognitive test performance) is (1) linear and (2) has the same slope in both ethnic groups. Additionally, covariance does not control for other unknown, unmeasured variables, which are related to years of education and which may also affect neuropsychological test scores. The advantage of the stratified random sampling procedure is that groups are well matched on education as well as any unmeasured variables related to years of education. However, as discussed earlier, variability in the characteristics of school experience of each ethnic group may not have been measured adequately by our years-of-education variable. This may have played a significant role in the current study, since most of our African American participants were raised in the South and were educated in segregated, 
rural schools. Years of education may be an adequate measure of school experience within an ethnic group, but may not be appropriate for analyses that compare ethnic groups. Therefore, neither statistical strategy used in the current study may have adequately corrected for dissimilarities in the educational experience of African American and white elders. Accurate measures of the aspects of schooling that are thought to affect neuropsychological test performance are needed to clarify the relationship of education to cognitive test performance among ethnic minority elders.

In addition to disparate educational experiences, cultural bias is another possible explanation for our findings of ethnic differences in test performance. Each of our measures was originally developed and standardized among whites. Traditional neuropsychological assessment is based on skills that are considered important within majority culture, but they may not be salient or valued within African American culture. ${ }^{5}$ Therefore, differences in salience of cognitive skills, exposure to items, and familiarity with certain problem-solving strategies could have attenuated the performance of African Americans on the neuropsychological battery. Cultural variability in response set, participant/examiner interactions, testtaking attitudes, and motivation during the testing session may also account for the ethnic group differences found on tests of verbal and nonverbal ability.

We found that ethnic group differences on our measure of verbal learning and memory was attenuated when groups were matched on education. This finding suggests that with proper educationcorrected norms, the SRT can be used to detect early dementia among ethnically diverse populations, since tests of verbal list learning and retention are highly sensitive measures in the differentiation of early Alzheimer's disease from both normal aging and other dementias such as Huntington's and Parkinson's. ${ }^{35}$

Discrepancies on a measure of figure memoryBVRT recognition-remained significant even after controlling for educational and occupational attainment. The BVRT matching task, which involves similar figures but does not include a memory component, also showed ethnic differences. Therefore, differences on the recognition task may be attributable to culturally based differences in decisionmaking about visuospatial material rather than nonverbal memory per se.

We found that after correcting for education, there was no difference between the scores of African Americans and whites on the MMSE Orientation task. This finding is consistent with that of a prior longitudinal study ${ }^{7}$ which found that after matching on education, there were no differences between African Americans and whites on the entire MMSE. However, other studies have reported ethnic differences on overall MMSE score even after controlling for demographic variables. ${ }^{8,9,20}$ It is possible that the non-Orientation items of the MMSE are most sen- sitive to cultural differences; however, further research is required to determine whether straightforward education corrections are adequate for interpreting the performance of ethnic minorities on the MMSE.

After controlling for education, we found no ethnic differences on the 15-item Boston Naming Test throughout each analysis. This finding is inconsistent with two previous studies, ${ }^{13,20}$ which found differences on measures of visual naming between education-matched groups of African Americans and whites. It is possible that the performance of our white participants on the Boston Naming Test items was attenuated compared with whites in other studies, because $40 \%$ of our white elders were immigrants who acquired English as a second language. Although participants were excluded if they did not report speaking English "very well," we have no validity testing of these self-reports. Variability in the specific items used as well as possible cultural and geographic differences in item frequency may also account for these discrepant findings.

Ethnic differences on our measure of verbal abstract reasoning were observed even after equating groups on years of education. The WAIS-R Similarities subtest requires the subject to associate items with increasing difficulty in abstraction. Prior research shows that African Americans categorize information, such as word lists, pictures, and situations, differently than whites. ${ }^{36}$ Therefore, culturally influenced variability in organization and information analysis (e.g., holistic versus detail-oriented, functional versus descriptive) may explain the ethnic group differences on this measure, and may have also influenced performance on the BVRT matching and recognition tasks. Cultural differences in organizational strategies may also explain the results of a recent investigation that found that Spanishspeaking individuals obtained significantly lower scores than English-speaking persons on the two BVRT tasks and the DRS Identities and Oddities subtest. ${ }^{19}$

We found that after matching groups on education, ethnic differences on letter fluency became nonsignificant but remained significant for category fluency. Both tasks tap linguistic and executive skills, and require the generation of words within a short period of time. However, category fluency involves an organization of semantic information component that may be more sensitive to cultural differences.

We used the neurologist's diagnosis as a "gold standard" for the selection of nondemented elders into the current study. Although we have no studies of reliability of the neurologist's diagnoses, and no proof that the functional measures used by the neurologist are culture free, our findings suggest that the neurologist's diagnoses, as well as the functional measures, were at least less biased than the neuropsychological measures. Specifically, there were no ethnic group differences on the two functional mea- 
sures in the context of significant educational and neuropsychological discrepancies.

Establishing age, education, and gender-corrected norms for African American elderly on widely used neuropsychological measures may help to decrease the risk of misdiagnosing African Americans as cognitively impaired based on their cognitive test performance. However, the educational and cultural experiences of African Americans vary depending on geographic, socioeconomic, and acculturative factors. Therefore, norms established in one region may not be applicable to all African Americans. Future studies should focus on identifying specific cultural and linguistic variables that affect test performance. When the influence of culture on neuropsychological test performance is better understood, measures can be created that differentiate between normal aging and dementia among ethnically diverse elderly with equal specificity.

\section{References}

1. Ardila A. Directions of research in cross-cultural neuropsychology. J Clin Exp Neuropsychol 1995;17:143-150.

2. Loewenstein DA, Arguelles T, Arguelles S, Linn-Fuentes P. Potential cultural bias in the neuropsychological assessment of the older adult. J Clin Exp Neuropsychol 1994;16:623-629.

3. Reynolds CR, Chastain RL, Kaufman AS, McLean JE. Demographic characteristics and IQ among adults: analysis of the WAIS-R standardization sample as a function of the stratification variables. J Sch Psychol 1987;23:323-342.

4. Kaufman AS, McLean JE, Reynolds CR. Sex, race, residence, region, and education differences on the 11 WAIS-R subtests. $\mathrm{J}$ Clin Psychol 1988;44:231-248.

5. Helms JE. Why is there no study of cultural equivalence in standardized cognitive ability testing? Am Psychol 1992;47: 1083-1101.

6. Neisser U, Boodoo G, Bouchard TJ, et al. Intelligence: knowns and unknowns. Am Psychol 1996;51:77-101.

7. Murden RA, McRae TD, Kaner S, Bucknam ME. Mini-Mental State Exam scores vary with education in blacks and whites. J Am Geriatr Soc 1991;39:149-155.

8. Gurland BJ, Wilder DE, Cross P, Teresi J, Barrett VW, Screening scales for dementia: toward reconciliation of conflicting cross-cultural findings. Int J Geriatr Psychiatry 1992; 7:105-113.

9. Bohnstedt M, Fox PJ, Kohatsu ND. Correlates of Mini-Mental Status Examination scores among elderly demented patients: the influence of race-ethnicity. J Clin Epidemiol 1994;47: 1381-1387.

10. Amante D, VanHouten VW, Grieve JH, Bader CA, Margules PH. Neuropsychological deficit, ethnicity, and socioeconomic status. J Consult Clin Psychol 1977;45:524-535.

11. Penk WE. Visual memory for black and white male heroin and nonheroin drug users. J Abnorm Psychol 1981;90:486-489.

12. Adams RL, Boake C, Crain C. Bias in a neuropsychological test classification related to education, age, and ethnicity. J Consult Clin Psychol 1982;50:143-145.

13. Roberts RJ, Hamsher KD. Effects of minority status on facial recognition and naming performance. J Clin Psychol 1984;40: $539-545$.

14. Heverly LL, Isaac W, Hynd GW. Neurodevelopmental and racial differences in tactile-visual (cross-modal) discrimination in normal black and white children. Arch Clin Neuropsychol 1986;1:139-145.
15. Bernard L. Halstead-Reitan neuropsychological test performance of black, Hispanic, and white young adult males from poor academic backgrounds. Arch Clin Neuropsychol 1989;4: 267-274.

16. Klusman LE, Moulton JM, Hornbostle LK, Picano JJ, Beattie MT. Neuropsychological abnormalities in asymptomatic HIV seropositive military personnel. J Neuropsychol Clin Neurosci 1991;3:422-428.

17. Miller EN, Bing EG, Selnes OA, Wesch J, Becker JT. The effects of sociodemographic factors on reaction time and speed of information processing. J Clin Exp Neuropsychol 1993;15; 66. Abstract.

18. Lichtenberg PA, Ross T, Christensen B. Preliminary normative data on the Boston Naming Test for an older urban population. Clin Neuropsychol 1994;8:109-111.

19. Jacobs DM, Sano M, Albert S, Schofield P, Dooneief G, Stern Y. Cross-cultural neuropsychological assessment: a comparison of randomly selected, demographically matched cohorts of English and Spanish-speaking older adults. J Clin Exp Neuropsychol 1997;19:331-339.

20. Welsh KA, Fillenbaum G, Wilkinson W, et al. Neuropsychological test performance in African American and white patients with Alzheimer's disease. Neurology 1995;45:22072211.

21. Ripich DN, Carpenter B, Ziol E. Comparison of AfricanAmerican and white persons with Alzheimer's disease on language measures. Neurology 1997;48:781-783.

22. Blessed G, Tomlinson BE, Roth M. The association between quantitative measures of dementia and of senile changes in the cerebral grey matter of elderly subjects. Br J Psychiatry 1968;225:797-811.

23. Schwab JF, England AC. Projection technique for evaluating surgery in Parkinson's disease. In: Gillingham FS, Donaldson MN, eds. Third symposium on Parkinson's disease. Edinburgh: E \& S Livingstone, 1969:152-157.

24. Katzman R, Brown T, Fuld P. Validation of a short orientation-memory-concentration test of cognitive impairment. Am J Psychiatry 1983;140:734-738.

25. Buschke H, Fuld PA. Evaluating storage, retention, and retrieval in disordered memory and learning. Neurology 1974; 24:1019-1025.

26. Benton AL. The visual retention test. New York: The Psychological Corporation, 1955.

27. Folstein MF, Folstein SE, McHugh PR. 'Mini-Mental State': a practical method for grading the cognitive state of patients for the clinician. J Psychiatr Res 1975;12;189-198.

28. Wechsler D. WAIS-R manual. New York: Psychological Corporation, 1981 .

29. Mattis S. Mental status examination for organic mental syndrome in the elderly patient. In: Bellack L, Karasu TB, eds. Geriatric psychiatry. New York: Grune and Stratton, 1976: $77-121$.

30. Kaplan E, Goodglass H, Weintraub S. Boston naming test. Philadelphia: Lea \& Febinger, 1983.

31. Benton AL, Hamsher de S K. Multilingual aphasia examination. Iowa City, IA: University of Iowa, 1976.

32. Goodglass H, Kaplan E. The assessment of aphasia and related disorders. Philadelphia: Lea \& Febinger, 1983.

33. Rosen W. The Rosen Drawing Test. Bronx, NY: Veterans Administration Medical Center, 1981.

34. Stern Y, Andrews H, Pittman J, Tatemichi T, Lantigua R, Mayeux R. Diagnosis of dementia in a heterogeneous population. Arch Neurol 1992;49:453-460.

35. Bondi MW, Salmon DP, Butters N. Neuropsychological features of memory disorders in Alzheimer's disease. In: Terry RD, Katzman R, Bick KL, eds. Alzheimer's disease. New York: Raven Press, 1994:41-63.

36. Shade BJ. African American patterns of cognition. In: Jones RL, ed. Black psychology. 3rd ed. Berkeley, CA: Cobb and Henry Publishers, 1991:231-247. 